\title{
CONTINUOUS VERSUS INTERMITTENT BOLUS EPIDURAL ANAESTHESIA IN ELDERLY SURGICAL PATIENTS
}

\author{
Yin X K*, Xiang Z G*, Prasai A*, Lamichhane N*
}

\section{ABSTRACT}

A prospective study of 70 elderly conventionally continuously randomized patients was done to compare the haemodynamic changes produced during continuous infusion versus intermittent bolus epidural anaesthesia. The hemodynamic parameters (Blood pressure, Heart rate) were slightly changed in continuous infusion group but there was no significant difference compared with baseline value $(p>0.05)$. Whereas, In bolus group, the hemodynamic parameters differed significantly compared with baseline values and the patients in group I. So conclusion of better hemodynamic stability in continuous infusion epidural anaesthesia than that in intermittent bolus epidural method in elderly is reached.

Key Words: Epidural anaesthesia, haemodynamic, intermittent bolus, continuous infusion.

\section{INTRODUCTION}

Epidural anaesthesia is usually administered for surgery in lower abdomen, perineum and lower extremities. Although General Anaesthesia (GA) is considered safe for any category of patients, it is not very safe when only halothene is used for long periods of GA. For those elderly patients with compromised heart lung functions, complications of GA are high. So epidural anaesthesia has a greater role for elderly patients from safety point of view. ${ }^{1}$ Epidural anaesthesia can be delivered in two ways; either by the continuous infusion using a syringe pump or by intermittent bolus method. There is no data regarding differences of haemodynamic changes after change in delivery pattern. Objective of our study is to compare the haemodynamic changes produced during continuous infusion versus intermittent bolus epidural anaesthesia in elderly patients.

\section{MATERIAL AND METHODS}

Seventy patients scheduled for lower abdominal or pelvic surgery were selected for this study. All of these patients were between 60 to 70 years of age and belonged to American Society of anaesthesiology (ASA) grade I, II or III. Thirty-nine patients were male and 31 were female. Ischaemic heart disease was demonstrated on ECG of 20 cases involved. The operations performed were trans-vesical prostatectomy, total abdominal hysterectomy with bilateral salphingo-oopherectomy, amputation of penis and partial cystectomy etc. The patients were randomized conventionally in two groups. Patient in group I received epidural anaesthesia by continuous epidural infusion using syringe pump and patients in group II received epidural anaesthesia by intermittent bolus injection method. All the patients were premedicated with $1 \mathrm{mg}$ Lorazepam orally at previous night and on the morning of the day of surgery.

* B. P. Koirala Memorial Cancer Hospital, Bharatpur, Chitwan, Nepal.

Address for correspondence : Dr. Xu Kao Yin

B.P. Koirala Memorial Cancer Hospital

Bharatpur, Chitwan, Nepal

Email: kaoyinxu@hotmail.com 
Intravenous infusion was started and vital signs were monitored before starting the procedure. According to the type and site of operation, epidural space was chosen at L1-2, L2-3 or L3-4 level. After confirming the epidural space by loss of resistance technique; an epidural catheter was introduced cephalad into epidural space. After placing it $3 \mathrm{~cm}$ in epidural space, it was fixed. Three milliliter of $2 \%$ xylocaine was administered through epidural catheter as a test dose to check for inadvertent intrathecal or vascular placement. Hypotension or marked motor block within 5 minutes of dose suggests intrathecal placement. ${ }^{1}$ Epidural catheter of patients in Group I were connected to the syringe pump, and a mixture of $1.5 \%$ xylocaine and $0.15 \%$ bupivacaine $(2 \%$ Xylocaine $7 \mathrm{ml}+0.5 \%$ bupivacaine $3 \mathrm{ml}$ ) was infused at the rate of $1 \mathrm{ml} /$ minute for 10 minutes and then at $6 \mathrm{ml} /$ hour until the end of surgery. The patients in group II received the same mixture of drug, $5 \mathrm{ml}$ bolus injections at a time, twice, 5 minutes apart. This $5 \mathrm{ml}$ bolus injection was repeated at an interval of 50 minutes each until the end of surgery. Thus all the patients in group I and II had received 13 $\mathrm{ml}$ mixture of xylocaine and bupivacaine into epidural space before starting the operation. During the operation, the patients received Ringer's lactate solution, initially at $15 \mathrm{ml} / \mathrm{kg} /$ hour and then maintained at $10 \mathrm{ml} / \mathrm{kg} /$ hour. Whole blood was transfused as and when necessary; $0.05 \mathrm{mg} / \mathrm{kg}$ midazolam was given intravenous and oxygen inhalation was maintained at $2 \mathrm{~L} /$ minute through nasal prongs. The patients were monitored continuously for oxygen saturation (Spo2), heart rate, blood pressure (NIBP, systolic, diastolic and mean arterial pressure (MAP)) and ECG. Values of these parameters before the administration of anaesthesia is considered to be the base line value for that particular patient. The lowest value for MAP and the widest fluctuation and its time was noted. Ephedrine was used intravenous whenever systolic Blood pressure was less than $90 \mathrm{~mm}$ hg or $30 \%$ less than the baseline value.

\section{Anaesthesia was evaluated as:}

Excellent: when the patient had adequate analgesia, good muscle relaxation and contracted bowel.

Satisfactory: when the patient required small dose of parenteral analgesic supplement.

Poor: when the patient needed general anaesthesia to continue the operation.

\section{STATISTICAL METHODS}

Pared t test was done to compare the mean values of the different parameters between the groups and within the group. $\mathrm{p}<0.05$ considered to be statistically significant.

\section{RESULTS}

There was no significant difference of age, sex, weight and type of disease between two groups ( $p>0.05)$. Induction time was between 15-20 minutes and was slightly longer in group I but the difference was not significant statistically $(\mathrm{p}>0.05)$.

The observed values of systolic, diastolic, mean arterial pressure and heart rate were not significantly different after 5 minutes of initial test dose in the two groups ( $>>0.05)$. These values were slightly reduced in group I patients after 30 minutes of induction, while were significantly reduced in group II $(\mathrm{P}<0.05)$. For detail see table I.

Heart rate was found to be slightly faster after epidural injection, but the difference was not significant statistically between two groups. Fifty percent of the patients in group II needed ephedrine to maintain blood pressure following epidural bolus injections while it was only $10 \%$ in group I that is statistically significant $(\mathrm{P}<0.01)$. Changes in MAP is listed in table II. 